\title{
Response surface optimization of conditions for clarification of carambola fruit juice using a commercial enzyme.
}

\begin{abstract}
Response surface methodology (RSM) was employed for simultaneous analysis of the effects of enzymatic treatment conditions of incubation time, incubation temperature and enzyme concentration on physical characteristics such as turbidity, clarity, viscosity, and color. In this study, a two-factor central composite design was used to establish the optimum conditions for the enzymatic treatment for clarification of carambola fruit juice. Carambola fruit juice was treated with pectinase enzyme at different incubation time (20-100 min), incubation temperature $\left(30-50{ }^{\circ} \mathrm{C}\right)$ and enzyme concentration $(0.01-0.10 \mathrm{v} / \mathrm{v} \%)$. These three variables were used as independent variables, whose effects on turbidity, clarity, viscosity and color were evaluated. Significant regression models describing the changes on turbidity, clarity, viscosity and color with respect to the independent variables were established with coefficient of determination, $\mathrm{R} 2$, greater than 0.70 . The results indicated that the enzyme concentration was the most important factor affecting the characteristics of the carambola fruit juice as it exerted a significant influence on most of the dependent variables. The recommended enzymatic treatment condition from the study was at $0.10 \%$ enzyme concentration at $30{ }^{\circ} \mathrm{C}$ for $20 \mathrm{~min}$.
\end{abstract}

Keyword: Carambola juice; Enzymatic treatment; Optimization; Response surface methodology. 